\title{
Living with Anxiety of Corona Qualitative Study
}

\author{
Dr. Jaya Bharti * , Prof. Pallavi Bhatnagar ${ }^{* *}$ \\ * Assistant Professor, Psychology Department, A.N.D.N.N.M.M., Harshnagar, Kanpur University \\ ** Professor And Former Head, Psychology Department, University Of Lucknow \\ DOI: 10.29322/IJSRP.10.06.2020.p10287 \\ http://dx.doi.org/10.29322/IJSRP.10.06.2020.p10287
}

\begin{abstract}
COVID-19 has emerged as the biggest global health crisis of the decade. What is essential to understand, that it is the concepts of community spread, Corona warrior, survival of the fittest immunity circle, immunity passport, hygiene, infection and safety etc. How people were perceiving corona? How were the coping with the fear and anxieties of corona? How realistic was their information bank? Purpose was the study to explore the experiences of people regarding corona according to locale (Rural and Urban Population). The data was thereafter content analysed for an in-depth understanding for their lived experiences. Both the groups have shown the resilience to give very realistic strategies for dealing with corona if we can tolerate the uncertainty of the situation instead of avoiding or running away from them that shows an opportunity for reoriented from towards life channelizing new direction and new energy.
\end{abstract}

\section{INTRODUCTION}

$\mathrm{W}$ hat was reportedly the beginning of a cluster of cases with pneumonia of unidentified aetiology in December, 2019 in Wuhan city in China (World Health Organization, 2020) soon became the deadly Corona virus 2 disease. By the end of April 2020, the disease had spread to over 213 countries, infected more than 2858,635 confirmed cases across world and resulted in an approximate 196295 deaths. The clinical picture being an epidemic of acute respiratory tract infection with rapid transmission of infection primarily through droplets, respiratory secretions and direct contact (Guo, Cao, Hong, Tan, Chen, Jin,2019).

The exponential rise in the number of cases succumbing to COVID-19 compelled World Health Organization (WHO) to refer to this outbreak a "Pandemic" (World Health Organization, 2020)

Pandemics and epidemics of new and re-emerging infectious disease are unpredictable but recurrent events that threaten global health and socio-economic security. It is of utmost importance to human health that there is capacity to conduct time-critical, patient-centred research during a pandemic because such research offers the best strategy for mitigating impact on health and society (Commission on a Global Health Risk Framework for the Future,2016; Lurie, Manolio, Patterson,2013; Rojek, Horby,2016).

COVID-19 has emerged as the biggest global health crisis of the decade. What is essential to understand, that it is the concepts of community spread, Corona warrior, survival of the fittest immunity circle, immunity passport, hygiene, infection and safety etc. which on the one hand, is building a wall of protection with community awareness and community mobilization towards strengthening public health against Corona. On the other hand, the pain, anxiety and fear of corona are also having a spill over effect over the whole community. Not just those who are infected and suffering but even those are quarantine and lockdown.

The authors speculated the existing scenario and found in the informal conversation with few people, common thread of angst (anxiety), uncertainty of existence, isolation, a quest for survival. Somewhere they are reminders of Frankl, May, Nietzel (Pioneers of existentialism) and Kabir mysticism (the eastern thought) on the same platform.

The impermanence and uncertainty seem so overwhelming that somewhere most of the people are making subvention to the ultimate insignificance of human life and the need to fill the void of emptiness. Some even use intellectualization as a defend. "Well! Everything passes, nothing last, so he has also gone". "This is the time of crisis for all of us, so we need to gear up over mental ability and be alert". "Well! This is a journey and ultimately it will come to an end". "Some philosophically sighted with 'Sadho Ye Murdon Ka Gaon..... Peer Mare, Pygambar Mari Hain, Mari Hain Zinda Jogi'(Oh Sadhu/Saint, this is the Village of the Dead.....The Saints Have Died.... The God-Messengers Die... The Life-Filled Yogis Die Too) (Explanation- The reality as we experience it every day is dynamic in nature - i.e., if there is one thing that is constant is the fact that everything is changing all the time. Whatever takes birth must die too, and vice-versa, what dies must be born also) and the other one is "Matti kahe kumhar se tu ka roundhe mohe ek din aisa ayega mai roundhungi tohe".(Explanation- Clay says to the Potter... Roundhe is an interesting word as it implies moulding, this line conveyed the idea that matter is never created nor destroyed, because one day we will become ashes, and nature will utilises that same matter to make another life. Whilst the potter moulds the clay today, such a day will come in the future, when the tables turn, and then he will be the clay. These ideas are the basis of a universal truth that most of us can deduce). Such statements intrigued the author to take up the chance of reaching out the people and connect with how their experiencing the crisis of COVID-19 around them.

\section{METHOD}

The research questions were- How people were perceiving corona? How were the coping with the fear and anxieties of corona? How realistic was their information bank? etc.

Purpose- To explore the experiences of people regarding corona according to locale. 
Using the existential paradigm an open ended schedule of "We, you and corona" was prepared, after telephonically taking the consent the schedule was sent to them over whats app and mail. The sample thus comprised of 200 respondents equally divided in rural and urban setting from Lucknow and Kanpur. The data were collected during one of the peak period (March to April 2020) of the COVID-19 outbreak in all over the world including India. The data was thereafter content analysed for an in-depth understanding for their lived experiences and their endeavour to fight against the panic, fear and crisis for corona.

\section{RESULTS AND DISCUSSION}

Content analysis was done. For each dimension the result are being shared. The most frequent themes are as follows:

A. Corona: Perceived meaning

B. Corona: Thought Spectrum across the three points of time-the past, the present and Future with reference to Corona

C. Corona: Continuous \& Dominant felling/Emotion

D. Victory of corona on Human being (exploring the situations when Corona defeated us)

E. Victory of Human being on corona (exploring the situations when we defeat Corona)

\section{A. Corona: Perceived meaning}

How do general population construe Corona, brought forth some fearful experiences from them. Five major response categories were (1) Incurable Disease (2) Death (3) Monster(Ravan)/Enemy (4) Infectious Disease (5) Darkness. Corona was construed predominately as "Incurable Disease" for the urban population $(\mathbf{8 0 \%})$, as evident by narrative like "This is a disease that does not have any solution, many well-known doctors in many countries are engaged in making its medicines, but so far no one has been able to succeed, what shall we say........ No solution of this CORONA and It can have many kinds of consequences if any member of the family has corona illness, then that member will take the whole family in their grip and the whole family may suffer as a result of this disease. It is better to stay away from it..... This disease is incurable".

On the other hand the experience of corona was predominantly that of a "Monster(Ravan)" for the rural population $(\mathbf{8 4 \%})$, as evident in the narrative "Hearing the name of CORONA, I miss the Demon/Monster, I am very scared, I feel anxious......Ramayana is coming on TV these days and Ravana (ten headed monster, a very important charcter in Ramayan, It is an Indian-television historical series, which aired between 1987 and 1988 on DD National....It is a television adaptation of the ancient Indian Hindu epic..... The series was reaired during the 2020 Coronavirus lockdown and broke several viewership records globally which includes setting the record for one of the most-watched TV show ever in the world ( i.e 77 million viewers on 16th April, 2020). Whenever I hear the name of Corona, then I feel corona and Ravana like an enemy of mine who wants to destroy the entire human race and wants to win all over, the only difference between Ravan and Corona is that Ravana only wanted to destroy those who did not listen to him........ but Corona wants to destroy the whole world, how I feel after hearing about Corona virus, I cannot even say it properly in words."

He"s not my husband anymore-we don"t have a relationship - I am his caregiver - our

marriage ended with his stroke-he has his room and I have mine-his stroke and

caregiving have affected my relationship with his children-they have alienated me

He"s not my husband anymore-we don"t have a relationship - I am his caregiver-our

marriage ended with his stroke-he has his room and I have mine-his stroke and

caregiving have affected my relationship with his children-they have alienated me

B. Corona: Thought Spectrum across the three points of time-the past, the present and Future with reference to Corona

Thought spectrum on the one hand thoughts reflection of the respondent of what thought came to them primarily regarding corona in the moths of Jan-March (Past). Further they were asked to report what thought are prominent in the 'Now and Here' in the months of April-June (Present). In the last they were asked to write about thoughts they would have regarding corona in the coming time that in the months of July-September (Future).

The responses pertaining to the reflections of the past that is Jan- March which predominately have four categories viz: 1) Animal Disease (2)Problem of another country(3)A news/ article(4) Illness of rich people. Thought content of urban population has more often etiological base of the thought on why of corona as "Animal Disease" (51\% Urban population) a respondent explained as follows:"People who consume meat, fish, rooster, goat, Pig, etc., according to me, the disease is more spread in purely Non-vegetarians because the disease has come from China and Chinese people's eat a bat, spider, etc there is no such animal which is not eaten in China, that is why nature has shown its wrath and we are all facing the consequences of this, according to me, this disease is caused by animals......... Therefore, all of us should stop eating meat, fish or any animal from today itself." Besides $\mathbf{5 0 \%}$ respondents reported the information in "news/article". The narrative below corroborate the same "I have heard so much about Corona, through TV, newspapers, news, magazines, etc. This disease is spreading in this country.....how many people have died in a country..... so many people in this country have been infected ..... These facilities have reduced in this country. ... So whoever I listen to has heard through the TV newspaper, Corona is still news for me"

Surprisingly the rural belt $\mathbf{( 8 8 \% )}$ reflected their initial thought regarding Corona as attributions to affluence and belonging to a particular group as "Illness of rich people". The following quotes explain her sentiments towards corona in the past: "Corona virus is a disease that spreads to the rich ... People who travel more abroad, live abroad, consume meat, fish, etc., the disease is spread by them. What about the poor... The poor do not have bread to eat, so how will they eat meat fish... If the poor do not have a bicycle, then what will sit in the airplane, then it is a disease of the rich. They travel abroad, they have this disease, those who have money, who can spend 
money in its treatment, they are getting.... According to this, this disease is also very sensible".

In the present frame of thoughts are more focused on the management of Corona as evident in the four major categories which emerge (1) Social Distancing(2) Hand wash(3)Stay locked in the house(4) Problem with no solution. Hence once again the urban population $\mathbf{( 8 5 \% )}$ ) predominantly had thoughts pertaining to "Social Distancing", a major strategy for management. The narrative below highlights the feelings of the participants, who were echoed by their fear "At Present Corona is my biggest fear.... To avoid this fear, we have to create social distance... I am trying to avoid thinking about Corona. Corona comes in my dreams too. Especially yesterday I dreamed that I am in the hospital ...... so today social distance is the only protection from Corona. I saw, I think it would be a big part of my life".

On the other hand, the mindset of the rural population $\mathbf{( 9 0 \% )}$ shows a more negative picture reported the dominant thoughts as the "Problem without any solution" respondent elaborated as: "What comes to mind is that life goes on as usual? You know that the outbreak of Corona started in March, but no medicine has been made yet, Even such powerful countries are unable to do anything...I believe it has no solution, life goes on simultaneously. We have to live with it .... We have to accept it".

Finally, the last point of thought continuum that is the future (July-September) brings to forth three major categories are:(1) Curable disease (2) Fear/ Anxiety(3)Stop going abroad. 80\% Urban population had a more positive mindset of conceiving Corona as a "Curable Disease" the following respondent narrative revealed how they perceived the Corona in Future "In the future, the corona will be such a disease, which will be possible to cure, because if you look back, there have been many terrible diseases that were initially untreated ..... But later their medicines and injections came. .... Later on or after a few months, medicines and injections of corona disease will also come... .which will play an important role in saving mankind". On the other hand their counterpart that is the rural respondents $(\mathbf{8 8 \%})$ clearly make a decision that they will "Stop going abroad". Somewhere they still feels that the disease has being brought from outside the country and still create a barrier there they would be scared. The narrative reflected their experiences "In the future, people will stop travelling abroad due to corona viruses, because people have associated corona with the country and abroad ... It has become thinking that anyone who goes to other countries will have a disease like Corona, Ebola. There will be a possibility. ...... People would be afraid to travel outside..... A few months ago, when people go to other countries and sit in airplanes, they would take their pictures, selfies and put them on Facebook. Everything is turned upside down. Nobody wants to tell anyone that if he has come from abroad, then in future the movement of people in other countries will be reduced...".

\section{Corona: Dominant feeling and emotion}

This dimension tapes the first feeling associated with Corona or with first spontaneous emotion aroused when they heard the word Corona. It brought forth voluminous data with content analysis leads to five exclusive responses categories viz: (1) Negative feeling/Behaviour (2) Loss of someone \& anxiety (3) Fear and anxiety (4) Injury pain (5) Personalized experience. In the urban sample, there was an overwhelming feeling of "Fear and Anxiety" with verbatim: "I feel very worried about Corona, very scared, the mind starts getting nervous, I don't understand what is happening, sometimes I feel like a mentally ill person ... ... I feel like screaming ... and sometimes it seems like I should not say anything to anyone, let alone ..... I have strange thoughts in my mind that make me afraid ......".

Their counterparts; the respondents from the rural belt also had an over pervasive response in terms of "Anxiety and Loss" amig tears $(86 \%)$. The views of the respondents on this matter were important following narrative reflected their sentiments: "I do not have to think about corona virus because I feel anxious about this disease all the time ...... there is always a fear of losing close one.....whenever someone goes out of the house , Then there is a fear in the mind ........ strange thoughts start coming in the mind that now it will come back safely or not the mind is very nervous When I look at the grocer, when I see a cleanser, it seems that it will remain alive or not, the thoughts and dreams of losing someone altogether haunt me day and night".

In such a turbulent state of mind. One is compelled to rethink to make choices to cope up. Hence, the last two dimension of the schedule taped the critical thinking and problem solving since of the respondents to facilitate them, to address the situations in terms of the win loose and loose win situations afresh.

D. Victory of corona on Human being (exploring the situations when corona defeated the human)

First they were asked to explore and identify the situations when Corona would win over them. In other words they were being made to explore the weak point or grey areas where they were less prepared to handle the disease and subsequently felt more vulnerable. The content analysis brought forth five major responses for the loose win situations viz: (1) Poor psychological well-being (2) Not taking necessary precautions (3) No interest in physical activity (4) Personalized Negative (5) Contact with medical professional, police, delivery boy. Majority of the Urban respondents (78\%) attributed the defeat to their "Poor psychological well-being" which is heartening with verbatim like: "When we are afraid ..... Anxious...frustrated...crying..... do not share our problems with family members...... and do not make any effort to be happy, then the corona virus wins.........All these things tell us that in future if we come in contact with someone who has corona, then we too will have hundred percent chances of being corona.".

On the other hand the respondents of the rural group predominantly reported on the concept with the caregiver or people in conscious with corona infected people $\mathbf{( 8 2 \% )}$ reported victory of corona as "Contact with medical professional, police, 
delivery boy". Community spread and minimizing contact somewhere show the mindset of the rural population with narrative: "CORONA wins over us when we come in contact with someone who is taking care of people who suffer with corona ..... like doctors who are serving people suffering from corona day and night. He is equally likely to have this disease.....because after how long he will be able to keep himself safe from it............. In the same way, the police advise people to stay in the house day and night ... I believe that people who are delivering goods from house to house during this difficult time ... .. the Cleaners who are engaged in cleaning, how long will they protect themselves from this disease ... they have $99 \%$ chance of getting this disease and if we come in contact with such people then we are equally likely Become. And corona wins over us".

E. Victory of Human being on corona (exploring the situations when corona defeated by human)

The other side of the coin is obtaining the win loose responses. That is exploring the strength of the research sample for wining over corona. The content analysis brought forth four major response categories viz: (1) Stay at home/Hum andar corona bahar (2) Take necessary Precautions/sanitizers (3) Mindful activities/yoga (4) Don't know. Where in three are concrete strategies and fourth is a confused mindset of I do not know.

$\mathbf{8 2 \%}$ of the urban population suggest "activities of mindfulness/Yoga" which is on a positive note for it is only being in the 'Now and Here' that would help us all too radically accept the painful reality of Corona in life with narrative "To win from Corona, we have to adopt yoga and practice on a regular basis... we have to give positivity to our thinking, only then our body will be healthy... and we will be able to defeat the corona" ; "Mindfulness" in this crisis of corona: "For me mindfulness motivates the mental strength to fight against Corona. If you have that mental strength, you will survive most situations like a pandemic. It is an ability to survive kind of and to stay calm on the inside......".

On the other hand $84 \%$ rural population give a more concise staying with a boundaries of home and therefore be protected response as "Stay at home/Hum andar corona bahar". Somewhere lockdown in different stages in India seems to be slowly be internalize for safety of oneself from all kind of danger with narratives like: "Will stay in the house... will follow all the guidelines stated by the government ....... When you stop yourself from getting out, then only you will win from Corona ......Stay at home";"We have only a small hut in the name of a house in which my family of 4 people We have to live, yet we are safe because we live in the same place, do not go out for fun... so it is safe... corona outside and me and my family inside of the hut".

\section{CONCLUSION}

Both the groups have shown the resilience to give very realistic strategies for dealing with corona if we can tolerate the uncertainty of the situation instead of avoiding or running away from them that shows an opportunity for reoriented from towards life channelizing new direction and new energy. Somewhere the crisis is being faced and the experience brings the change in perception. Living it, being with it, repairs one to face it with grasses, strength, resilience and hope.

\section{REFERENCES}

[1] Commission on a Global Health Risk Framework for the Future. The neglected dimension of global security: a framework to counter infectious disease crises. 2016.http://nam.edu/GHRFreport

[2] Guo, Y., Cao, Q., Hong, Z. et al. The origin, transmission and clinical therapies on coronavirus disease 2019 (COVID-19) outbreak - an update on the status. Military Med Res 7, 11 (2020). https://doi.org/10.1186/s40779020-00240-0

[3] Lurie N, Manolio T, Patterson AP, et al. . Research as a part of public health emergency response. N Engl J Med 2013; 368: 1251-1255. [PubMed] [Google Scholar]

[4] Rojek AM, Horby PW. Modernising epidemic science: enabling patientcentred research during epidemics. BMC Med 2016; 14: 212. [PMC free article] [PubMed] [Google Scholar]

[5] WHO. Clinical management of severe acute respiratory infection when novel coronavirus (nCoV) infection is suspected. https://www.who.int/publications-detail/clinical-management-of-severeacute-respiratory-infection-when-novel-coronavirus-(ncov)-infection-issuspected

\section{AUTHORS}

First Author - Dr. Jaya Bharti, Assistant Professor, Psychology Department, A.N.D.N.N.M.M., Harshnagar, Kanpur University Second Author - Prof. Pallavi Bhatnagar, Professor And Former Head, Psychology Department, University Of Lucknow 